\title{
Assimetrias na participação desportiva: os casos de Portugal e Espanha no contexto europeu
}

\author{
Salomé Marivoet*
}

\begin{abstract}
Resumo: as estatísticas sobre a participação desportiva têm vindo a revelar claras assimetrias entre os países europeus. As taxas de participação desportiva são bastante mais elevadas nos países do Norte do que nos do Sul. Nos países do Norte encontra-se uma maior paridade entre a participação masculina e feminina, um envolvimento mais elevado dos jovens no desporto, e a diminuição da prática desportiva ao longo da vida é menos acentuada. Contrariamente, nos países do Sul, a participação feminina é mais fraca e mais distante da dos homens, o envolvimento dos jovens é menor, e a diminuição da prática desportiva ao longo da vida mais acentuada. Com base no caso de Portugal e Espanha, o artigo pretende demonstrar que estas assimetrias resultam dos valores de cultura física e desportiva enraizados nos hábitos da população, assim como características socioeconômicas e políticas de cada país.

Palavras-chave: Desporto, Cultura, Participação Desportiva, Portugal, Espanha.
\end{abstract}

O aumento dos tempos livres e a diversificação do mercado dos consumos culturais vieram produzir alterações nos modos de vida nas sociedades mais industrializadas, afirmando-se o lazer como um espaço de realização humana (Rojek 1995). Se por um lado, a procura desportiva no âmbito das práticas de lazer aumentou grandemente, por outro, assistiu-se à intensificação da competição desportiva, e ainda, à crescente comercialização de espectáculos e diversificados serviços desportivos. O desporto veio assim a ganhar uma maior expressão nestas sociedades, e a tornar-se um dos seus setores econômicos (Andreff et Nys 1986; Lavoie 2000; Primault 2001).

A generalização do desporto como prática de lazer inserida nos estilos de vida, contou ainda com o incremento de políticas públicas, que vieram a ser promovidas na maioria das sociedades ocidentais desde a segunda metade do século XX (Callède 1987;

* Socióloga, docente na Faculdade de Ciências do Desporto e Educação Física da Universidade de Coimbra, e especialista representante de Portugal junto ao projeto europeu COMPASS.

Movimento, Porto Alegre, v. 9, n. 2, p. 53-70, maio/agosto de 2003 
Heinemann 1997; Rowe 2001). Os novos valores de cultura físicodesportiva que se vieram a afirmar, enalteceram o desporto para todos, rompendo com a tradição do desporto moderno que o restringia aos indivíduos com melhores condições físicas para as prestações de natureza competitiva (Elias et Dunning 1994).

Como marca da sociedade pós-industrial, os lifestyle sports institucionalizaram-se e difundiram-se, dadas as atuais tendências de globalização não só contribuírem para a uniformização dos mercados, mas também dos estilos de vida padronizados segundo os valores dominantes nas sociedades ocidentais (Bale 2000; Miller et al. 2001; Maguire et al. 2002).

Contudo, a aculturação dos estilos de vida assumem contornos específicos que ultrapassam os simples efeitos de moda. Mesmo na Europa, apesar das tendências que apontam para uma crescente generalização das práticas desportivas no seio das populações, continuam a persistir assimetrias que interessará conhecer e aprofundar. Neste propósito, desenvolvemos uma breve análise das participações desportivas européias, incidindo em especial nos casos de Portugal e Espanha.

\section{Obstáculos à quantificação das práticas desportivas}

A construção de estatísticas suficientemente abrangentes das práticas desportivas das populações tem vindo a enfrentar vários obstáculos, dada as tendências para a diversificação das atividades físicas e dos envolvimentos. Deste modo, a definição de desporto, isto é, das práticas consideradas desportivas, e a uniforme avaliação dos diferentes envolvimentos, constituem as principais dificuldades com que os estudos se debatem (Mussino 1997).

O conceito de desporto presente na Carta Européia do Desporto, aprovada em 1992 na $7^{\text {a }}$ Conferência dos Ministros Europeus Responsáveis pelo Desporto dos países do Conselho da Europa, tem vindo a tornar-se uma referência na construção de estatísticas desportivas, ainda que o seu carácter demasiado abrangente continue a colocar dificuldades. ${ }^{1}$

1 Segundo o texto da Carta Européia de Desporto: "Entende-se por 'desporto' todas as formas de atividades físicas que, através de uma participação organizada ou não, têm por objetivo a expressão ou o melhoramento da condição física e psíquica, o desenvolvimento das relações sociais ou a obtenção de resultados na competição a todos os níveis".

Movimento Porto Alegre, v. 09, n. 2, p. 53-70, maio/agosto de 2003 
Se a pertinência do conhecimento da participação desportiva nas diferentes sociedades satisfaz necessidades de avaliação da situação, com possibilidades de se constituírem referências na definição de políticas públicas ou de investimentos privados, elas também têm vindo a contribuir para uma maior compreensão do desporto como prática cultural.

Ainda que com diferenças, a maioria dos estudos nos diferentes países tem vindo a revelar que as participações desportivas são superiores no sexo masculino, nos jovens, nos indivíduos com níveis de escolaridade mais elevada e inseridos em grupos sociais com maiores recursos (AAVV 1999). Esta tendência do comportamento da população coloca conseqüentemente exigências na fiabilidade das estatísticas da participação desportiva, dado as amostras necessitarem de ser proporcionalmente estratificadas segundo estas variáveis.

Também, a delimitação do universo da população em estudo requer uniformidade para fins de comparação, dada a idade se apresentar como uma variável estruturante da participação desportiva. Se se juntar a estes obstáculos o fato de estas estatísticas serem consideradas como indicadores de desenvolvimento, o que não as torna indiferentes, ficam mais claras as dificuldades que se apresentam na quantificação das práticas desportivas. Na realidade, os enviesamentos podem ser enormes, quando as estatísticas produzidas se baseiam em universos etários que não contemplam as franjas da população mais envelhecida, ou não têm em consideração na estratificação das amostras o peso real das variáveis que se apresentam como estruturantes da prática desportiva.

Contudo, estão sendo feitos esforços no sentido da uniformização dos critérios utilizados na construção das estatísticas da participação desportiva para fins de comparação internacional. Uma primeira tentativa data de 1979, levada a efeito num estudo multinacional promovido pelo CDDS, Comitê Diretor do Desenvolvimento do Desporto do Conselho da Europa, onde se desenvolveu a construção de um conjunto de indicadores desportivos (CE.CDDS (1982)25).

Mais recentemente, o projeto europeu COMPASS ( $\mathrm{Co}$ ordinated monitoring of participation in sport), criado em 1996, tem vindo a desenvolver uma base metodológica com vista à harmonização das estatísticas da participação desportiva. Contando atualmente com um conjunto alargado de países, o proje-

Movimento, Porto Alegre, v. 9, n. 2, p. 53-70, maio/agosto de 2003 
to COMPASS conta já com um conjunto de estatísticas divulgadas que nos fornecem maiores possibilidades na realização de análises comparadas. ${ }^{2}$

\section{Tendências dos hábitos desportivos}

Da comparação das estatísticas da participação desportiva nos seis países europeus divulgadas pelo projeto COMPASS, podemos concluir que se assiste a acentuadas assimetrias entre a realidade dos países do Norte e os do Sul da Europa, apresentando os primeiros taxas muito mais elevadas do que os segundos. Nos países do Norte, a Suécia em 1997 apresentava uma participação desportiva de 70\%, a Grã-Bretanha em 1996 de 67\%, e a Irlanda em 1994 de 64\%. ${ }^{3}$ Quanto às participações desportivas dos países do Sul, a Espanha em 1995 apresentava uma taxa de 31\%, e, Portugal em 1998 e Itália em 1995 respectivamente de 23\% (http://w3.uniromal.it/Compass).

Numa análise mais atenta dos indicadores COMPASS nos diferentes países, verificamos que as participações intensivas, quer sejam no âmbito da competição ou não, não expressam em termos da população que representam as assimetrias que traduzem as taxas de participação global, com exceção do caso da Suécia que continua a apresentar valores elevados. A participação desportiva superior a 120 vezes por ano na Suécia é de 37\%, na Grã-Bretanha e Irlanda respectivamente de $18 \%$, em Portugal de $11 \%$, em Espanha de 9\%, e na Itália de 5\% (http:// w3.uniromal.it/Compass).

2 Da informação referente aos oito países divulgadas no site deste projeto, seis apresentam uma adequada harmonização. Os critérios metodológicos na construção das estatísticas da participação desportiva para fins de comparação internacional requerem a existência de amostras representativas da população entre os 16 e os 74 anos estratificadas segundo a idade, sexo, habilitações literárias e território, e ainda, o recolhimento da informação que permita quantificar os componentes dos indicadores COMPASS (freqüência, competição e organização da prática desportiva).

3 Apesar da França estar integrada no projeto COMPASS, o último estudo de 2001 não foi considerado para fins de comparação internacional, dado não ter avaliado os indicadores definidos nos pressupostos metodológicos. Contudo, os resultados dos estudos da prática desportiva situam-na na realidade dos países do Norte. Os dados do estudo do INSEP de 1985 apontavam para uma participação desportiva da população entre os 12 e 74 anos na ordem dos 74\% (Irlinguer et al. 1987: 35). Mais recentemente, o estudo de 2001 realizado pelo MJS/INSEP sob a coordenação de Mignon et Truchot revelou uma participacão desportiva de $61 \%$ da população entre os 15 e os 75 anos ("déclarent spontanément"), e de $83 \%$ por contabilização de práticas não consideradas de desportivas pelos inquiridos ("question de repêchage") (Duret 2001: 18).

Movimento Porto Alegre, v. 09, n. 2, p. 53-70, maio/agosto de 2003 
As acentuadas assimetrias ficam assim a dever em grande parte, às práticas desportivas orientadas para o lazer e integradas nos estilos de vida considerados ativos ou os designados lifestyle sports. Deste modo, os dados sugerem-nos que as diferenças que atualmente se encontram nas participações desportivas entre os países do Sul e Norte da Europa revelam diferentes concepções de desporto enraizadas nos hábitos das populações. ${ }^{4}$

Apesar dos hábitos desportivos nos países ibéricos apresentarem alguma proximidade quando comparados com os dos países do Norte, a participação desportiva na Espanha tem vindo a revelar-se superior à registada em Portugal. Os estudos da população entre os 15 e os 60 anos realizados durante a década de oitenta em cada um dos países, revelaram uma participação desportiva em 1985 de 34\% na Espanha, e em 1988 de 27\% em Portugal (Ferrando 1997: 46; Marivoet 1998: 57).

Enquanto em Portugal se tratou do primeiro estudo, o que revela uma tardia preocupação das entidades públicas no conhecimento desta matéria, na Espanha, Manuel Garcia Ferrando (1997: 46), autor dos estudos espanhóis desde a década de oitenta, salienta o crescimento da participação desportiva no seu país, que se situava em 1975 nos $22 \%$, e em 1980 nos $25 \%$.

Embora os estudos realizados posteriormente nestes dois países apresentem dificuldades de comparação com os anteriores, dado contemplarem universos mais alargados da população em estudo, os dados parecem apontar para a desaceleração do crescimento da participação desportiva. ${ }^{5}$ Ao compararmos os indicadores COMPASS nos dois países, continuamos a constatar uma superior participação desportiva global na Espanha (31\%), face à registada em Portugal $(23 \%){ }^{6}$

4 Nos casos de Espanha e Portugal, esta realidade é igualmente visível na deficiente estruturação da oferta face às diferentes disposiçôes da procura (Ferrando 1997; Marivoet 2001a, 2002).

5 Portugal alargou o universo do estudo aos 74 anos no levantamento de 1998, de acordo com os pressupostos metodológicos do projeto europeu COMPASS, enquanto o estudo de 1995 na Espanha, um ano antes da criação do referido projeto, até aos 65 . No caso espanhol, a participação desportiva para a população entre os 16 e as 65 anos era em 1995 de 39\%, embora a estimativa para a população entre os 16 e 74 anos seja de 31\% (Ferrando 1997: 46; http://w3.uniroma1.it/ Compass). No caso português, a participação da população entre os 15 e os 60 anos apresentou em 1998 uma taxa de $27 \%$, isto é, idêntica à do estudo de 1988 para o mesmo universo etário (Marivoet 2001a: 15)

6 Será importante referir que o número médio de desportos praticados por cada praticante é bastante superior na Espanha do que em Portugal, respectivamente 2,4 e 1,4 (Ferrando 1997: 59; Marivoet 2001a: 65).

Movimento, Porto Alegre, v. 9, n. 2, p. 53-70, maio/agosto de 2003 
No entanto, quando analisamos as diferentes participações segundo os diferentes envolvimentos, verificamos, que a superior participação desportiva na Espanha fica a dever a existência de uma maior prática irregular e ocasional (v. quadro 1). Os indicadores revelam ainda que os hábitos desportivos dos portugueses apresentam uma maior intensidade de prática do que os espanhóis.

Quadro 1. Participação desportiva na Espanha e Portugal

\begin{tabular}{|c|c|c|}
\hline Indicadores CoMPASS & $\begin{array}{c}1995 \\
\text { Espanha }\end{array}$ & $\begin{array}{c}1998 \\
\text { Portugal }\end{array}$ \\
\hline $\begin{array}{c}\text { Competitiva, Organizada, Intensiva } \\
(\geq 120 \text { vezes por ano })\end{array}$ & 2 & 3 \\
\hline Intensiva $(\geq 120$ vezes por ano $)$ & 7 & 8 \\
\hline $\begin{array}{c}\text { Regular, Competitiva e/ou Organizada } \\
(\geq 60 \text { e }<120 \text { vezes por ano })\end{array}$ & 4 & 3 \\
\hline $\begin{array}{c}\text { Regular, Recreativa } \\
(\geq 60 \text { e }<120 \text { vezes por ano) }\end{array}$ & 10 & 4 \\
\hline Irregular $(\geq 12$ e $<60$ vezes por ano) & 6 & 1 \\
\hline Ocasional $(\geq 1$ e $<12$ vezes por ano) & 69 & 77 \\
\hline Não participantes em práticas desportivas & 2 & 4 \\
\hline
\end{tabular}

Fonte: http://w3.uniroma1.it/Compass

Os dados parecem sugerir uma maior valorização do desporto orientado para o melhoramento das prestações na sociedade portuguesa, ${ }^{7}$ ainda que ambos os países apresentem taxas de participação relativamente próximas quando comparadas com as dos países do Norte europeu.

Contudo, ao analisarmos a participação desportiva na população mais escolarizada em ambos os países, constatamos uma maior efetivação da aquisição de hábitos de prática, sobretudo na sociedade espanhola como se pode ver no quadro 2. Este fato denota que o papel desempenhado pela instituição escolar na socialização dos valores de cultura físico-desportiva, tende a contrariar tradições cristalizadas nas parcelas da população menos escolarizada.

7 A comparação entre os dados portugueses de 1988 e 1998 para a população dos 15 aos 60 anos é a este respeito reveladora. Apesar da participação desportiva global ter estagnado, verificou-se um crescimento de mais dois pontos percentuais na participação do desporto de competição federado, passando de $3 \%$ para $5 \%$, enquanto situação inversa ocorreu no desporto de lazer (Marivoet 2001a: 15).

Movimento Porto Alegre, v. 09, n. 2, p. 53-70, maio/agosto de 2003 
A participação desportiva segundo as classes sociais apresenta igualmente taxas superiores nos grupos com maiores recursos, independentemente da idade e do sexo (Ferrando 1997: 73; Marivoet 2001: 59). As diferenças entre a participação segundo os grupos sociais são ainda assinaladas no estudo português ao nível das afinidades entre estes e os desportos praticados. ${ }^{8}$ Como Pierre Bourdieu (1987) bem salientou, a uniformização dos consumos culturais passa igualmente por lógicas distintivas nas afinidades que se estabelecem entre os grupos sociais e as práticas, onde as desportivas constituem um bom exemplo.

Quadro 2. Participação desportiva segundo a escolaridade na Espanha e Portugal

\begin{tabular}{|c|c|c|}
\hline & $\begin{array}{c}\mathbf{1 9 9 5} \\
\text { Espanha } \\
\mathbf{1 6} \text { aos 65 anos }\end{array}$ & $\begin{array}{c}\mathbf{1 9 9 8} \\
\text { Portugal } \\
\mathbf{1 5} \text { aos 74 anos }\end{array}$ \\
\hline Sem estudo & 13 & 5 \\
\hline Primária & 19 & 15 \\
\hline Curso Superior Médio & 60 & 35 \\
\hline Ensino Superior & 66 & 49 \\
\hline
\end{tabular}

Fonte: Ferrando 1997: 51; Marivoet 2001a: 57.

Os dados disponível parecem sugerir que as taxas de participação desportiva registadas em Portugal e Espanha, mas também na Itália, isto é, nos países do Sul com informação disponível, denotam a cristalização de valores tradicionais de cultura físico-desportiva. Segundo vários autores, este fato não pode deixar de ser compreendido se não se tiver presente as determinações exercidas pelos regimes fascistas, que durante décadas levaram a cabo políticas desportivas elitistas e fortemente disciplinadoras (Ferrando 1990; Rosário 1996; Porro \& Missaglia 1997; Marivoet, 1998).

8 Apesar do peso do futebol no conjunto das modalidades praticadas continuar a fazer-se sentir nas afinidades dos grupos sociais, sendo a primeira modalidade mais praticada por todos eles com exceção dos Empresários e Quadros Superiores. A importância do futebol no conjunto dos diferentes desportos também se manifesta na sociedade espanhola. Na Espanha, o futebol é praticado por $36 \%$ dos praticantes, e em Portugal representa $30 \%$ das modalidades praticadas (Ferrando 1997: 59; Marivoet 2001a: 66). Em matéria de desportos praticados a comparação internacional apresenta enormes dificuldades, não só devido à designação, sobretudo aqueles que sendo praticados de forma informal adquirem em alguns estudos designações diferentes dos nomes oficiais das respectivas federações, como varia a informação, que ora é apresentada face à população geral, ou face aos praticantes, ou ainda face às modalidades praticadas.

Movimento, Porto Alegre, v. 9, n. 2, p. 53-70, maio/agosto de 2003 
Nos casos de Portugal e Espanha, as políticas orientadas para a democratização do desporto só vieram a se concretizar a partir da instauração dos regimes democráticos em meados da década de setenta do século $\mathrm{XX}$, embora numa conjuntura econômica internacional menos favorável, e no caso português apresentando grandes fragilidades (Ferrando 1997; Marivoet et Malveiro 2001). Contudo, a determinação dos contextos socioculturais e históricos nas assimetrias entre os países do Norte e do Sul da Europa são conhecidas, e bem mais abrangentes do que as que se fazem sentir no espaço desportivo. ${ }^{9}$

\section{Desporto ao longo da vida}

Apesar da prática desportiva diminuir com a idade nas diferentes sociedades européias, encontram-se especificidades que poderão contribuir para uma melhor compreensão das assimetrias existentes (v. figura 1)..$^{10}$ Nos países do Norte, onde como já referimos as taxas de participação são mais elevadas do que nos do Sul, os jovens apresentam uma maior generalização de hábitos desportivos, o que sugere uma maior eficácia na transmissão de valores de cultura físico-desportiva por parte das instituições socializadoras nestas sociedades.

Também, o decréscimo da participação desportiva ao longo das gerações adultas é menos acentuado nestes países do que nas sociedades do Sul europeu. Estes fatos fazem denotar como a prática desportiva se constitui um hábito cultural decorrente dos valores de cultura físico-desportiva predominantes em cada sociedade.

9 Os países do Norte fortemente industrializados e com uma tradição de políticas de Welfare-State apresentam maiores taxas de escolaridade e eqüidade social, enquanto os do Sul têm assistido nas décadas recentes a uma passagem direta da importância do setor primário para o terciário, comportando populações menos escolarizadas, e maiores assimetrias sociais e territoriais (Silva 2002). No caso da participação desportiva segundo o território, as comparações apresentam alguma dificuldade, no entanto, é possível concluir que os hábitats de menor dimensão (menos de 2000 habitantes), marcadamente rurais e envelhecidos, apresentam as taxas mais baixas na Espanha e Portugal (Ferrando 1997: 51; Marivoet 2001a: 31). Quanto às assimetrias regionais, também nos dois países as regiões mais rurais apresentam participações desportivas inferiores às respectivas médias nacionais (na Espanha as Comunidades Autônomas da Extremadura, Rioja e Galícia; e em Portugal a Zona Centro). Inversamente, as regiões com maiores aglomerados urbanos apresentam valores acima das médias nacionais (na Espanha, Madrid, Baleares, Cataluña e Navarra; e em Portugal: Lisboa e Vale do Tejo, e Norte com Grande Porto) (Ferrando 1997: 52/53; Marivoet 2001a: 23).

10 No site do projeto COMPASS os dados referentes à participação desportiva segunda a idade fornecem informacão sobre a participação intensiva ( $\geq$ a 120 vezes por ano), e a participação ocasional (<12 vezes por ano) agrupada com a não participação. Os dados do gráfico 1 são o complementar do segundo agrupamento referido, o que nos permite saber a participação desportiva superior a 12 vezes por ano. 
Nos casos de Portugal e Espanha, a prática desportiva superior a 12 vezes por ano abrange cerca de metade do grupo dos jovens entre os 16 e 19 anos, ${ }^{11}$ verificando-se uma taxa ligeiramente superior na participação dos jovens portugueses, enquanto no caso espanhol esta se verifica nas gerações adultas intermediárias (v. figura 1).

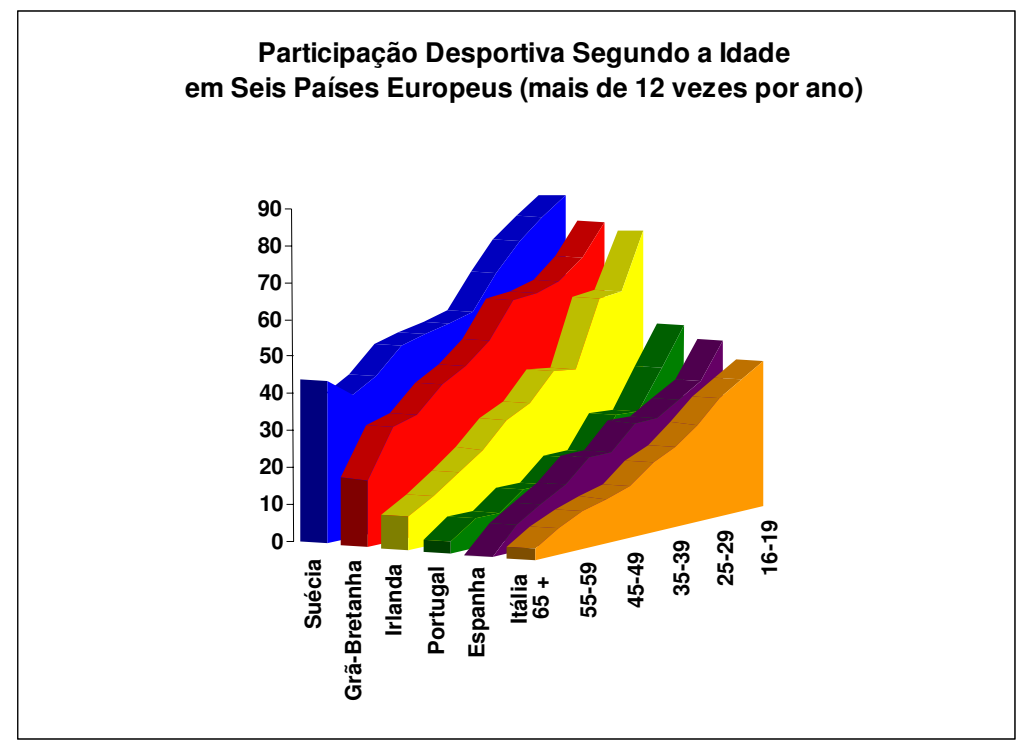

Fonte: http://w3.uniroma1.it/Compass

A participação desportiva segundo a idade nos países ibéricos sugere igualmente que na sociedade espanhola os novos valores de cultura físico-desportiva se encontram mais generalizados do que na sociedade portuguesa, ainda que em menor dimensão do que a verificada nos países do Norte.

11 Não é possível identificar a evolução da participação desportiva segunda a idade nos estudos de Portugal e Espanha realizados entre as décadas de oitenta e noventa. Contudo, os dados sugerem uma quebra da participação desportiva no escalão mais jovem das amostras. Em 1985 os resultados espanhóis apontavam para uma taxa de participação desportiva dos jovens entre os 15 e os 18 anos de $62 \%$ (Ferrando 1990: 77), claramente superior à de 1995 (46\%), ainda que nesta última não sejam consideradas as práticas de menos de 12 vezes por ano, e se refira aos jovens entre os 16 e 19 anos. Os dados espanhóis de 1995 apresentam uma taxa de participação desportiva dos jovens entre os 16 e os 24 anos de $60 \%$, não sendo assim possível estabelecer uma rigorosa comparação (Ferrando 1997: 49). Quanto aos resultados dos estudos portugueses verificou-se uma quebra de $4 \%$ na participação desportiva dos jovens entre os 15 e os 19 anos entre 1988 e 1998, tendo passado de $55 \%$ para $51 \%$ (1\% pratica menos de 12 vezes por ano) (Marivoet 1998: 58; 2001a: 55).

Movimento, Porto Alegre, v. 9, n. 2, p. 53-70, maio/agosto de 2003 


\section{Diferenças de gênero nas práticas desportivas}

A determinação dos valores de cultura físico-desportiva na participação torna-se igualmente visível nas relações de gênero que têm lugar neste espaço social. Muito embora se verifique uma tendência na maior participação masculina face à feminina nos países europeus considerados na presente análise, com excepção da Suécia que apresenta uma paridade, as diferenças tendem a ser maiores nos países do Sul face aos do Norte (v. figura 2$). .^{12}$

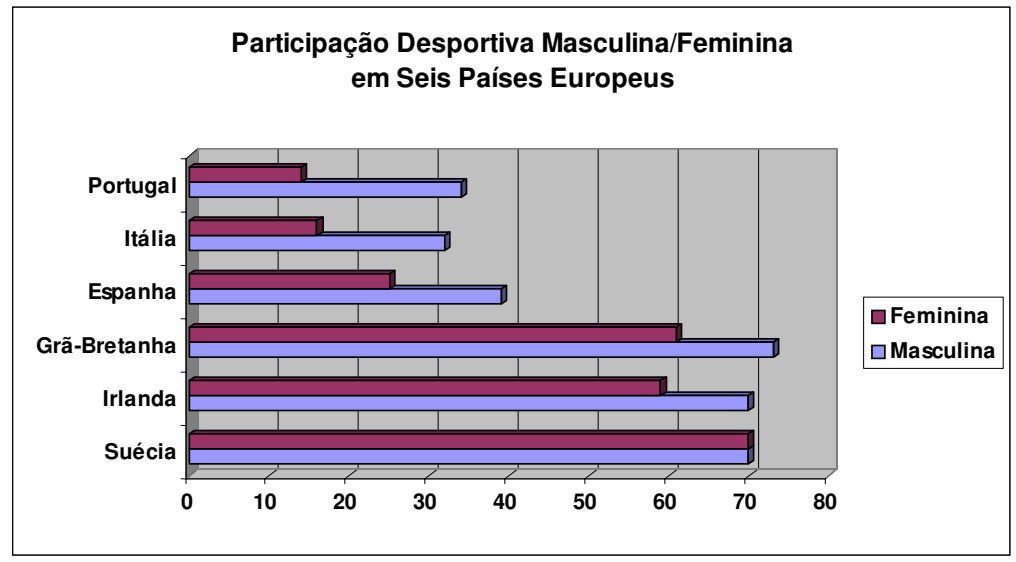

Fonte: http://w3.uniroma1.it/Compass

Dado o peso das mulheres na estrutura demográfica das populações, as diferenças entre os sexos contribuem em larga medida para as acentuadas assimetrias da participação desportiva no espaço europeu. Segundo as teorias feministas, a menor participação feminina no desporto denota relações de gênero marcadas pela dominação hegemônica da cultura masculina (Bryson 1994; Messner 1994).

Para vários autores desta corrente teórica, o espaço desportivo não só produz como reproduz esta relação de dominação, ao socializar as novas gerações nos valores dominantes da cultura mas-

$12 \mathrm{Na}$ França, o estudo de 2001 revelou uma participação desportiva masculina superior à feminina, embora próxima, tal como nos países do Norte, respectivamente de 76 e $70 \%$ (Duret 2001: 22).

Movimento Porto Alegre, v. 09, n. 2, p. 53-70, maio/agosto de 2003 
culina, que privilegiam a força física e a competição como símbolos de virilidade (Hargreaves 1994; Birrel et Cole 1994; Birrel 2001).

No entanto, estamos assistindo a mudanças nas relações de gênero nas sociedades ocidentais, quer no espaço desportivo quer nos demais, ainda que se esteja longe de uma verdadeira igualdade de oportunidades entre os sexos (Birrel et Cole 1994). Também, a crescente centralidade do corpo nas sociedades ocidentais tem vindo a incitar a procura de práticas desportivas com vista à manutenção da forma física, assistindo-se a uma reconfiguração das relações de gênero no que diz respeito às performances corporais (Whitson 1994; Giddens 1994; Lipovetsky 1994; Michela et Parisoli 2002).

Na realidade, as transformações nas relações de gênero no espaço desportivo são visíveis na aproximação da participação desportiva feminina e masculina na maior parte das sociedades europeias em análise. No entanto, quando se analisa a participação no desporto de competição, intensivo e organizado, as assimetrias entre os sexos aumentam drasticamente como se pode ver no quadro $3,{ }^{13}$ fazendo denotar que este espaço das práticas desportivas continua a ser um espaço marcadamente masculino.

Quadro 3. Indicador COMPASS da participação desportiva competitiva, organizada e intensiva

\begin{tabular}{|c|c|c|c|}
\hline & Masculina & Feminina & M/F \\
\hline Espanha - 1995 & 4 & 1 & 2 \\
\hline Grã-Bretanha - 1996 & 8 & 2 & 5 \\
\hline Irlanda - 1994 & 11 & 3 & 7 \\
\hline Itália - 1995 & 3 & 1 & 2 \\
\hline Portugal - 1998 & 6 & 1 & 3 \\
\hline Suécia - 1997 & 17 & 8 & 12 \\
\hline
\end{tabular}

Fonte: http://w3.uniroma1.it/Compass

13 No caso francês os resultados do estudo MJS/INSEP de 2001 revelaram uma participação desportiva de competicão (Pratiques avec licence et compétition) de 17\% masculina e 5,7\% feminina (Duret 2001: 22). Apesar destes dados não contemplarem a freqüência da prática, e conseqüentemente não serem comparáveis com os dados compilados no quadro 3 (apenas se consideram as práticas superiores a 120 vezes por ano), revelam uma nítida diferença entre as participações masculinas e femininas neste setor.

Movimento, Porto Alegre, v. 9, n. 2, p. 53-70, maio/agosto de 2003 
Nos casos da Espanha e de Portugal, a participação desportiva competitiva, organizada e intensiva das espanholas e das portuguesas é idêntica e bastante diminuta. No entanto, a participação global segundo os sexos denota que as espanholas apresentam uma prática desportiva mais generalizada do que as portuguesas, o que numa primeira leitura sugere a existência de uma maior aquisição de hábitos por parte das primeiras (v. quadro 4).

Quadro 4. Participação desportiva masculina/feminina na Espanha e Portugal

\begin{tabular}{|c|c|c|c|c|}
\hline & $\begin{array}{c}\text { Espanha } \\
\mathbf{1 5} \text { aos } \mathbf{6 0} \\
\text { anos } \mathbf{1 9 8 5}\end{array}$ & $\begin{array}{c}\text { Portugal } \\
\mathbf{1 5} \text { aos } \mathbf{6 0} \text { anos } \\
\mathbf{1 9 8 8}\end{array}$ & $\begin{array}{c}\text { Espanha } \\
\text { Indicadores } \\
\text { COMPASS } \\
\mathbf{1 9 9 5}\end{array}$ & $\begin{array}{c}\text { Portugal } \\
\text { Indicadores } \\
\text { COMPASS } \\
\mathbf{1 9 9 8}\end{array}$ \\
\hline Masculina & 42 & 37 & 39 & 34 \\
\hline Feminina & 22 & 18 & 25 & 14 \\
\hline Participação & 34 & 27 & 31 & 23 \\
\hline
\end{tabular}

Fonte: Ferrando 1997: 49; Marivoet 2001b: 116.

Embora a participação dos espanhóis e das espanholas seja superior à dos portugueses e portuguesas, as diferenças entre os sexos são nitidamente mais elevadas do que nos países do Norte. Contudo, a tendência de crescimento verificada na Espanha parece ter vindo a aproximar a participação masculina e feminina, enquanto em Portugal se verifica o contrário, isto é, um afastamento. ${ }^{14}$

Para uma melhor compreensão das diferenças entre a participação masculina e feminina nos países ibéricos, que de resto se assemelha à realidade italiana, será interessante ter presente algumas das tradições nas relações de gênero nos quotidianos domésticos, assim como a estrutura familiar dos países do Sul europeu, onde os tamanhos médios dos agregados tendem a apresentar os índices mais elevados. ${ }^{15}$

14 No caso espanhol, a participação desportiva masculina/feminina para a população dos 15 aos 65 anos era em 1995 respectivamente de 48 e 30\% (Ferrando 1997: 49). No caso português, os dados de 1998 referentes à população entre os 15 e 60 anos revelaram uma participação desportiva masculina de $39 \%$, e feminina de $16 \%$ (Marivoet 2001b: 116).

15 Segundo dados do Eurostat de 1996, o tamanho médio dos agregados familiares nos países do Sul apresentava valores superiores à média da UE situada nos 2,77 (Espanha 3,14, Portugal e Itália respectivamente 3,01, e a Grécia 2,93), (Ap. Silva 2002: 47).

Movimento Porto Alegre, v. 09, n. 2, p. 53-70, maio/agosto de 2003 
Apesar da crescente entrada das mulheres no mercado de trabalho, que no caso português assume uma taxa superior à média dos países da União Européia, ${ }^{16}$ os conjugues parecem continuar a não colaborar na divisão das tarefas domésticas, como fez notar um estudo do Eurostat, onde $70 \%$ das portuguesas, e $80 \%$ das espanholas assim o afirmaram, recolhendo os valores mais elevados neste item (Ap. Almeida et al. 1998: 57).

As vivências dos quotidianos com que são confrontadas as mulheres nestes dois países, agravada no caso português pela taxa superior de atividade feminina, fazem denotar uma clara escassez de tempo livre, com reflexos diretos na menor participação desportiva que apresentam. Haverá contudo a referir que o tempo livre se apresenta como um dos fatores explicativos, pois entre as gerações adultas, e sobretudo nas mais idosas, onde os níveis de escolaridade são menores, ainda se fazem sentir os preconceitos de gênero que as afastaram enquanto jovens das práticas desportivas, para além das deficiências na adequada e acessível oferta às disposições da procura feminina.

\section{Apontamento conclusivo}

Da leitura e discussão das estatísticas comparáveis da participação desportiva nos países europeus, podemos concluir que se encontram acentuadas assimetrias. As taxas de participação desportiva são muito mais elevadas nos países do Norte do que nos do Sul, denotando uma maior generalização do desporto nos primeiros.

Esta constatação sugere-nos que as assimetrias decorrem dos valores de cultura físico-desportiva enraizados nos hábitos das populações dos diferentes países, que apenas podem ser compreendidos se tivermos presente as características socioeconômicas e culturais, assim como as diferentes políticas desportivas que neles têm tido lugar.

Nos países do Norte, encontra-se uma maior aproximação da participação feminina à masculina, um maior envolvimento dos jovens no desporto, assim como o decréscimo da prática não

16 Segundo os dados da OCDE (2000), a taxa de emprego feminino nos países da União Européia era de 53,1\% em 1999. Portugal apresentava uma taxa de 59,5\%, a Grécia um ano antes de 40,3\%, a Espanha de 38,3\%, e a Itália de 38,1\% (Ap. Silva, 2002: 43).

Movimento, Porto Alegre, v. 9, n. 2, p. 53-70, maio/agosto de 2003 
se torna tão acentuado ao longo da vida. Contrariamente, nos países do Sul, a participação feminina é mais diminuta e afastada da masculina, o envolvimento dos jovens no desporto é menor, e o decréscimo da prática desportiva com a idade é mais acentuado.

No entanto, se a maior permanência de hábitos desportivos ao longo da vida nos países do Norte faz denotar uma ruptura com a tradicional concepção de desporto, que o restringe aos praticantes com as melhores condições físicas, já a participação no desporto de competição, organizado e intensivo denota o contrário. Neste setor, predominantemente masculino, as participações femininas são bastante diminutas, não se encontrando grandes diferenças entre as realidades dos países do Norte e do Sul.

Apesar dos países ibéricos apresentarem taxas de participação desportiva próximas, quando comparadas com a realidade do Norte europeu, a da Espanha é claramente superior à registada em Portugal. Este fato deve-se, em grande parte, à maior participação nas práticas de menor regularidade, já que nas intensivas as taxas são ligeiramente superiores na sociedade portuguesa. Deste modo, os dados sugerem que na sociedade espanhola os valores de cultura físico-desportiva se encontram mais generalizados do que na sociedade portuguesa, embora se assista a um abrandamento do crescimento em ambos os países.

A instituição escolar parece desempenhar um papel importante em ambos os países, na socialização dos valores de cultura físico-desportiva, contrariando as tendências em largas faixas da população menos escolarizada que não incorporaram hábitos de prática. Contudo, como já referimos, os jovens destes países apresentam um menor envolvimento nas práticas desportivas do que os dos países do Norte.

A prática desportiva tende assim a apresentar-se como um hábito cultural, e deste modo, as elevadas taxas de participação desportiva resultantes da generalização dos lifestyle sports não são suscetíveis de serem explicadas pelas interpretações do senso comum, que não raras vezes as atribuem aos efeitos contagiantes da moda. Por fim, podemos concluir desta breve análise que as assimetrias na participação desportiva só se poderão compreender, se se tiver presente as diferenças na generalização dos novos valores de cultura físico-desportiva, e as ações e instituições que os têm vindo a promover em cada sociedade.

Movimento Porto Alegre, v. 09, n. 2, p. 53-70, maio/agosto de 2003 


\begin{abstract}
Asimetrias en la Participación Deportiva. El caso de Portugal y España en el contexto europeo.

Resumen: las estadísticas acerca de la participación deportiva revelan evidentes asimetrías entre los países europeos. Las tasas de participación son mucho más elevadas en los países del Norte que en los del Sur. En los países del Norte existe una mayor paridad entre la participación masculina y femenina, una dedicación más importante de los jóvenes al deporte y la disminución de la práctica a lo largo de la existencia es menos acentuada. En los países del Sur, la participación femenina es más reducida y contrasta aún más con la de los hombres, la dedicación de los jóvenes al deporte es menor, y la disminución de la práctica a lo largo de la existencia más marcada. Apoyándose sobre los casos de Portugal y España, el artículo muestra que dichas asimetrías proceden de los valores de cultura física y deportiva anclados en las costumbres de las poblaciones así como de las características socio económicas y políticas de cada país.
\end{abstract}

Palabras clave: Deporte, Cultura, Participación Deportiva, Portugal, España.

A Lack of Symmetry in Sports Activities. The cases
of Portugal and Spain within the European Context
Abstract: statistics bearing on sports activities show a
clear asymmetry between European countries.
Participation rates are much higher in Northern than in
Southern countries. In Northern countries one can find
a greater equal share between women's and men's
participation, a larger commitment of young people,
and the decrease of practise all along a lifetime is less
marked. In the South, women's participation is lower,
contrasting more with that of men, young people's
commitment is weaker, and practise decrease is more
evident in a lifetime. Leaning on the cases of Spain and
Portugal, this paper points out that theses lacks of
symmetry arise from the values of physical training
and sports rooted in the populations' habits, as well as
in the socio-economic and political characteristics of
each country.
Keywords: Sport, Culture, Sports Activities, Portugal,
Spain.

Movimento, Porto Alegre, v. 9, n. 2, p. 53-70, maio/agosto de 2003 


\section{Referências}

AAVV, Sports Participation in Europe, London, UK Sport, 1999, pp. 65.

ALMEIDA, A. et al, Relações Familiares: Mudanças e Diversidade in VIEGAS, J.M. et COSTA A.F. (orgs) Portugal, que Modernidade?, Oeiras, Celta Editora, 1998, pp. 45-78.

ANDREFF, W. et NYS J-F., Économie du Sport (4), Paris, Presses Universitaires de France, 2001, pp. 127.

BALE, J., Human Geography and the Study of Sport in J. COAKLEY et E. DUNNING (eds) Handbook of Sports Studies, London, SAGE Publications, 2000, pp. 171-186.

BOURDIEU, P. Programme pour une sociologie du sport in Choses dites, Paris, Les Éditions de Minuit, 1987, pp. 203-216.

BIRREL, S. et COLE, C. (eds), Women, Sport, and Culture, Champaign, Human Kinetics, 1994, pp. 408.

BIRREL, S., Feminist Theories for Sport in J. COAKLEY et E. DUNNING (eds) Handbook of Sports Studies, London, SAGE Publications, 2000, pp. 61-76.

BRYSON, L., Sport and the Maintenance of Masculine Hegemony in S. BIRREL et C. COLE (eds) Women, Sport, and Culture, Champaign, Human Kinetics, 1994, pp. 47-64.

CALLĖDE, J-P., L'Esprit Sportif. Essai sur le développement associatif de la culture sportive, Bordeaux, Presses Universitaires de Bordeaux, 1987, pp. 194.

DUNNING, E. Sport as a Male Preserve: Notes on the Social Sources of Masculine Identity and its Transformations in S. BIRREL et C. COLE (eds) Women, Sport, and Culture, Champaign, Human Kinetics, 1994, pp. 163-179.

DURET, P., Sociologie du Sport, Paris, Armand Colin, 2001, pp. 208.

ELIAS N. et DUNNING, E., Sport et civilisation la violence maîtrisée, France, Éditions Fayard, 1994, pp. 393

FERRANDO, M., Aspectos Sociales del Deporte. Una reflexión sociológica, Madrid, Alianza Editorial Consejo Superior de Deportes, 1990, pp. 323.

FERRANDO, M., Los Españoles y el Deporte, 1980-1995. Un estudio sociológico sobre comportamientos, actitudes y valores, Madrid, COEDITAN Consejo Superior de Deportes (MEC), 1997, pp. 226.

GIDDENS, A., Modernidade e Identidade Pessoal, Oeiras, Celta Editora, 1994, pp. 209.

HARGREAVES, J., Sporting females. Critical issues in the history and sociology of women's sports, London, Routledge, 1994, pp. 331.

IRLINGER, P., LOUVEAU C., MÉTOUDI, M, Les Pratiques Sportives des Français, Paris, INSEP, 1987, pp. 666.

Movimento Porto Alegre, v. 09, n. 2, p. 53-70, maio/agosto de 2003 
LAVOIE, M., Economics and Sport in J. COAKLEY et E. DUNNING (eds) Handbook of Sports Studies, London, SAGE Publications, 2000, pp. 157-170.

LIPOVETSKY, G., O Crepúsculo do Dever. A Ética Indolor dos Novos Tempos Democráticos, Lisboa, Publicações Dom Quixote, 1994, pp. 320.

MAGUIRE, J. et al., Sport Worlds. A Sociological Perspective. Champaign, Human Kinetics, 2002, pp. 242.

MARIVOET, S. Aspectos Sociológicos do Desporto, Lisboa, Livros Horizonte, 1998, pp. 127.

MARIVOET, S. Hábitos Desportivos da População Portuguesa, Lisboa, Instituto Nacional de Formação e Estudos do Desporto (MJD), 2001a, pp. 194.

MARIVOET, S. O Género e o Desporto: Hábitos e Tendência, ex ?quo, Oeiras, $n^{\circ}$ 4, 2001b, pp. 115-132.

MARIVOET, S. Os Equipamentos Desportivos Face às Tendências da Procura in Seminário Equipamentos Desportivos. Novas Perspectivas de Gestão, Évora, AMDE, 2002, pp. 71-85.

MARIVOET, S. et MALVEIRO, O, Les Rapports entre l'État et le Mouvement Associatif au Portugal (1984-1999) in A. MENAUT et M. RENEAUD (orgs) Sport de haut niveau. Sport professionnel en région(s), Bordeaux, MSHA, pp121134.

MESSNER, M. Sport and Male Domination: The Female Athlete as Contested Ideological Terrain in S. BIRREL et C. COLE (eds) Women, Sport, and Culture, Champaign, Human Kinetics, 1994, pp. 65-80.

MICHELA, M. et PARISOLI, M., Penser le corps, Paris, Presses Universitaires de France, 2002, pp. 181.

MILLER, T. et al. Globalization and Sport, London, SAGE Publications, 2001, pp. 160.

MISSAGLIA, G. et PORRO, N. Cultural change and organizational innovation in a mass movement for sport for all: the case of UISP in P. NARDIS et al. (eds) Sport: Social Problems, Social Movements, Roma, Edizioni SEAM, 1997, pp. 210-221.

MUSSINO, A. (org), Statistica e Sport: non solo numeri, Roma, Società Stampa Sportiva, 1997, pp. 261.

HEINEMANN, K. Sport for all in Germany. A social movement or political power? in P. NARDIS et al. (eds) Sport: Social Problems, Social Movements, Roma, Edizioni SEAM, 1997, pp.176-182

PRIMAULT, D. La incidencia del deporte sobre el empleo en Francia y en Europa, Deporte Y Documentación, Málaga, n² 29, 2001, pp. 133-151.

ROJEK, C. Decentring Leisure. Rethinking Leisure Theory, London, SAGE Publications, 1995, pp. 215.

ROSÁRIO, A., O Desporto em Portugal. Reflexo e Projeto de uma Cultura, Lisboa, Instituto Piaget, 1996, pp. 495.

Movimento, Porto Alegre, v. 9, n. 2, p. 53-70, maio/agosto de 2003 
ROWE, N. El panorama social del deporte en Inglaterra. Una revisión de los resultados de investigación y sus implicaciones para la política pública, Deporte Y Documentación, Málaga, n² 29, 2001, pp.152-166.

SILVA, P.A. O Modelo de Welfare da Europa do Sul: Reflexões sobre a utilidade do conceito, Sociologia Problemas e Práticas, Oeiras, n 38, 2002, pp. 25-59.

WHITSON, D. The Embodiment of Gender: Discipline, Domination, and Empowerment in S. BIRREL et C. COLE (eds) Women, Sport, and Culture, Champaign, Human Kinetics, 1994, pp. 353-371. 